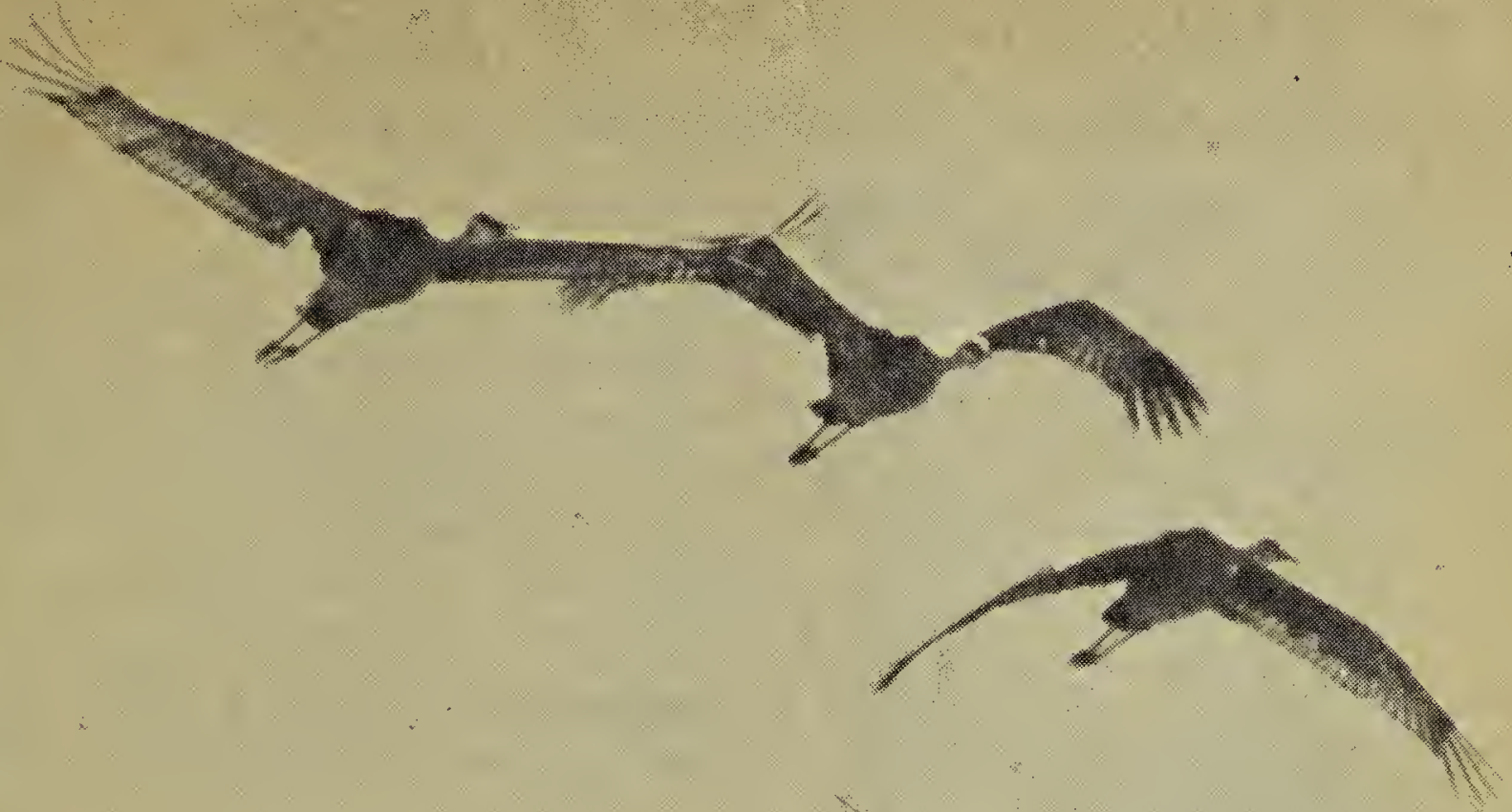

Photo by F. W. Lahrman

Sandhills in flight. Last Mountain Lake

The Saskatchewan Natural History Society recently proposed that the Dept. of Natural Resources establish a wildlife refuge at the end of Last Mountain Lake, especially for the protection of the Whooping Cranes and Sandhill Cranes. This is in line with the resolution re: the protection of Sandhill Cranes passed at the Annual Meeting in October, 1959. If you are interested in the development of such a wildlife refuge, support your Society in its request. Public interest in these projects helps guide governmental policy. It would help if you would write to your IMLA and ask for the establikhment of such a refuge. If you can, send a copy of your letter to the Editor so that the Society knows how much support it has.

\title{
Eliminate Sandhill Crane and Duck Damage to Crops
}

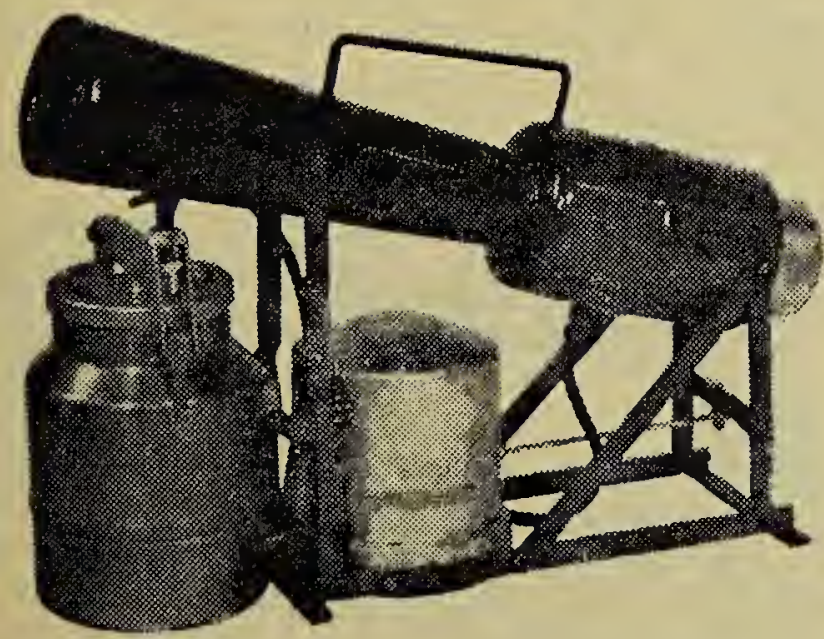

The SCARE-AWAY is a rugged, heavy duty unit operating inexpensively on carbide and water or on acetylene.

The SCARE-AWAY produces fully automatic harmless thunderclap ex- plosions at either regular or irregular intervals which will eliminate forever the loss and nuisance caused by birds in your crops.

The SCARE-AWAY operating on carbide and water costs $\$ 65.00$ in Saskatoon. Since this machine must be serviced once every 24 hours and since it may be difficult to get to the machine during a prolonged spell of wet weather you may want to convert to acetylene. The greater efficiency of the acetylene operation more than pays for the additional $\$ 20$ expense and for the rental charge for the acetylene tank.

The SCARE-AWAY is made in Europe. Investigate now for supplies are limited and time is required for ordering and shipping. Address inquiries to Tom Sterling, 2217 Munroe Ave., Saskatoon.-Advertisement. 